\title{
Evaluation of the effects of ground shaking and static volumetric strain change on earthquake-related groundwater level changes in Taiwan
}

\author{
Wen-Chi Lai ${ }^{1,2}$, Kuo-Chin $\mathrm{Hsu}^{2}$, Chjeng-Lun Shieh ${ }^{1,3}$, Youe-Ping Lee ${ }^{4}$, \\ Kuo-Chang Chung ${ }^{4}$, Naoji Koizumi ${ }^{5}$, and Norio Matsumoto ${ }^{5}$ \\ ${ }^{1}$ Disaster Prevention Research Center, National Cheng-Kung University, Taiwan \\ ${ }^{2}$ Department of Resources Engineering, National Cheng-Kung University, Tainan City, Taiwan \\ ${ }^{3}$ Department of Hydraulic and Ocean Engineering, National Cheng Kung University, Tainan City, Taiwan \\ ${ }^{4}$ Water Resource Agency, Ministry of Economic Affair, Taiwan \\ ${ }^{5}$ Geological Survey of Japan, National Institute of Advanced Industrial Science and Technology (AIST), Tsukuba, Japan
}

(Received May 1, 2009; Revised December 21, 2009; Accepted December 30, 2009; Online published June 17, 2010)

\begin{abstract}
Between 2001 and 2005, the Disaster Prevention Research Center of National Cheng-Kung University established a groundwater observation network consisting of 16 wells. Most of these were located along active faults for research on earthquake-related groundwater changes. They were selected mainly from among the 550 groundwater observation wells of the Water Resources Agency (WRA), which monitors and manages groundwater resources in Taiwan. The groundwater level was observed at a resolution of $0.2 \mathrm{~mm}$ at the wells. The depths of the well screens ranged between 80 and $252 \mathrm{~m}$. Groundwater level data at six of the 16 wells were analyzed between 2003 and 2006 in an evaluation of such data for use in detecting earthquake-related groundwater level changes. The strain sensitivities of the groundwater level at these six wells ranged between 0.1 and $0.5 \mathrm{~mm} / 10^{-9}$, indicating that an analysis of groundwater level data at these six wells can detect volumetric strain changes on the order of $10^{-9}$. Coseismic and/or postseismic groundwater level changes associated with 17 earthquakes in and around Taiwan whose magnitudes were $\geq 6$ were also analyzed. Our analysis shows that ground shaking seems the main reason for earthquake-related changes but that the acceleration of ground shaking cannot always explain the observed groundwater level changes.
\end{abstract}

Key words: Groundwater, earthquake, ground shaking, strain, water level, Taiwan.

\section{Introduction}

Reports of groundwater level changes induced by earthquakes are widespread in historical records, and such changes have been investigated in China, Japan, the former U.S.S.R., and the USA since the 1970s (Wakita, 1975; Roeloffs, 1988, 1996; Matsumoto et al., 2007). The study of earthquake-related groundwater level changes is also important within the context of gathering data on earthquakerelated natural hazards, such as postseismic landslides and debris flows, liquefactions of soil, and groundwater pollution caused by the mixing of radioactive or other high-risk wastes (Inverson and Major, 1986; Carrigan et al., 1991; Todorovska and Trifunac, 1999). Montgomery and Manga (2003) reviewed the reported observations of such changes and classified them in relation to earthquake magnitude and epicentral distance. However, their conclusions, which are based on observations of independent events by many different researchers, have a number of uncertainties arising from different mechanisms and site effects. It is usually difficult for earthquake-induced groundwater level changes to be explained quantitatively, although there are some exceptions to the rule, such as those reported by Igarashi

Copyright (c) The Society of Geomagnetism and Earth, Planetary and Space Sciences (SGEPSS); The Seismological Society of Japan; The Volcanological Society of Japan; The Geodetic Society of Japan; The Japanese Society for Planetary Sciences; TERRAPUB.

doi:10.5047/eps.2009.12.008 and Wakita (1991), Quilty and Roeloffs (1997), Akita and Matsumoto (2001), and Koizumi et al. (2004).

On September 21, 1999, a large $M_{\mathrm{w}} 7.6$ earthquake occurred near Chi-Chi in central Taiwan, subsequently denoted the Chi-Chi earthquake (Shin et al., 2000). The Chi-Chi earthquake caused many groundwater changes at several hundred Water Resource Agency (WRA) wells in Taiwan. This event has become a rare and well-documented example of earthquake-induced groundwater level changes measured together with seismological data sets (Wang et al., 2001; Lai et al., 2004) from a dense network of threecomponent accelerators stationed in Taiwan (Shin et al., 2000). Based on analyses of data collected on the observed groundwater level changes in the 1999 Chi-Chi earthquake, geologists, geophysicists, and hydrologists have become aware of the significance of research on earthquake-related groundwater level changes. In 2001, the National Science Council (NSC) in Taiwan funded the WRA to initiate a 5-year research program on earthquake-related groundwater changes under the comprehensive national program called "Program on Earthquake and Active fault Research (PEAR)". The main purpose of the program is to increase the resolution of the existing groundwater monitoring system and to obtain high-quality data for studying earthquake-related groundwater changes. The Disaster Prevention Research Center (DPRC) of National ChengKung University established 16 groundwater monitoring 
wells by the end of 2005 in cooperation with the Geological Survey of Japan, National Institute of Advanced Industrial Science and Technology (AIST).

Here, we introduce our groundwater observation network and report the preliminary results of our analyses on data collected at six of the 16 wells between November 2003 and December 2006. The other ten wells could not be analyzed in this context due to insufficient data for this period. Earthquake-related groundwater level changes are compared to observed seismic accelerations and to inferred coseismic static volumetric strain changes at the wells.

\section{Observation}

\subsection{Tectonic setting in Taiwan}

The island of Taiwan is located on the active subduction plate boundary between the Eurasian plate and the Philippine Sea plate (Chang et al., 2003). East of Taiwan, the Philippine Sea plate subducts northward beneath the Eurasian plate along the Ryukyu subduction system. South of Taiwan, the Philippine Sea plate overrides the crust of the South China Sea at the Manila trench, which extends northward from the Philippines to a latitude of about $21.5^{\circ} \mathrm{N}$ (Fig. 1). Consequently, Taiwan is located in an active arc-continent collision zone and is seismically very active. This is illustrated by the occurrence of 17 earthquakes of $\geq M_{\mathrm{W}} 6.0$ in and around Taiwan between November 2003 and December 2006 (Table 1, Broadband Array in Taiwan for Seismology, 2009; Kao and Jian, 2001).

\subsection{Procedure for choosing observation wells}

The WRA of the Ministry of Economic Affairs, Taiwan, has a groundwater observation network distributed primarily in the plains of Taiwan for monitoring groundwater resources. In 2003, the network included 228 observation stations with 550 observation wells, distributed throughout nine major groundwater areas (Water Resource Agency, 2005). Each station has one to five observation wells that are screened at different depths, varying between 10 and $320 \mathrm{~m}$. Therefore, there are more wells than stations. The groundwater levels are measured and recorded on digital data loggers hourly or on strip-chart analog recorders. The accuracy and resolution of the water level data are 2 and $1 \mathrm{~cm}$, respectively. The observations are downloaded monthly and managed by WRA. Because the wells of the WRA are spatially dense and maintained systematically, we chose the observation wells for our study from among those of the WRA.

The wells were chosen as follows. First, we chose wells that were located no more than $10 \mathrm{~km}$ from active faults (Central Geological Survey, 2000). The well water level data of WRA were used to check for artificial disturbances and the effects of rainfall. However, some of the chosen wells still show relatively large artificial disturbances. The effects on rainfall can be roughly divided into two types, based on duration. The first, which we call short-term rainfall effects, occurs just after a rainfall and continues for a few to several days. In confined groundwater, this effect is probably related to the loading of the rainfall. The second, which we call long-term rainfall effects, starts some time after the rainfall and continues for $>10$ days, and seems to show a recharge and discharge of groundwater. Long-term

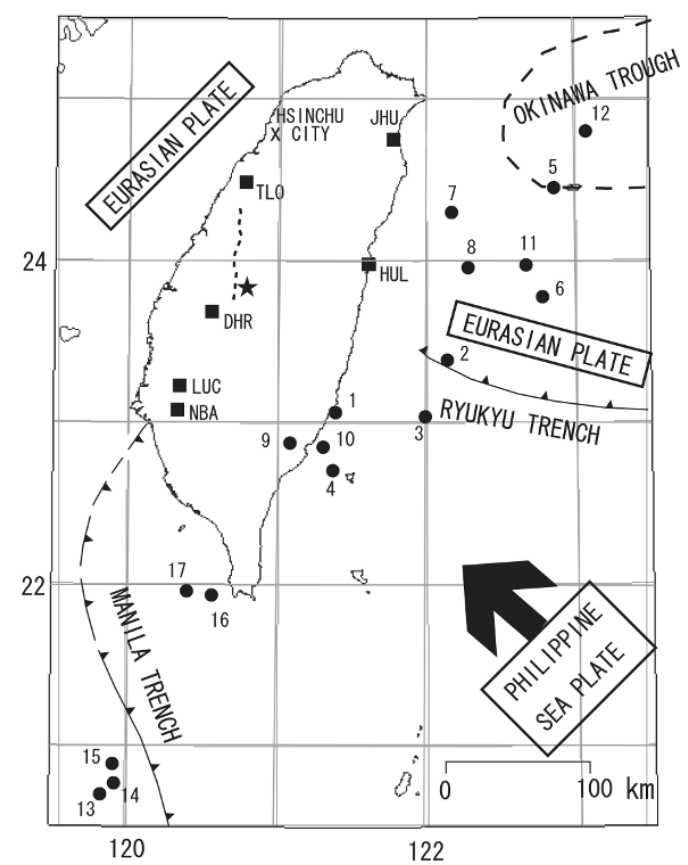

Fig. 1. Tectonic setting of Taiwan, observation wells (solid squares), and earthquakes (solid circles with numbers) in Table 1. A solid star denotes the epicenter of the 1999 Chi-Chi earthquake. A dotted line shows the Chelungpu fault, which is the earthquake fault of the 1999 Chi-Chi earthquake.

Table 1. List of the earthquakes of $\geq M_{\mathrm{W}} 6.0$ (December 2003-December 2006).

\begin{tabular}{ccccccc}
\hline No. Date* & Time* & Lat. & Long. & Depth $(\mathrm{km}) \mathrm{Mw}^{* *}$ \\
\hline 1 & Dec. 10, 2003 & $4: 38$ & 23.07 & 121.40 & 10.0 & 6.6 \\
2 & Feb. 4, 2004 & $3: 24$ & 23.38 & 122.15 & 4.0 & 6.0 \\
3 & May 16, 2004 & $06: 04$ & 23.05 & 121.98 & 12.5 & 6.0 \\
4 & May 19, 2004 & $7: 04$ & 22.71 & 121.37 & 8.7 & 6.5 \\
5 & Oct. 15, 2004 & $4: 08$ & 24.46 & 122.85 & 58.8 & 7.0 \\
6 & Nov. 8, 2004 & $15: 54$ & 23.79 & 122.76 & 10.0 & 6.6 \\
7 & Nov. 11 2004 & $2: 16$ & 24.31 & 122.16 & 27.3 & 6.0 \\
8 & Sep. 6, 2005 & $9: 16$ & 23.96 & 122.28 & 16.8 & 6.1 \\
9 & Apr. 1 2006 & $18: 02$ & 22.88 & 121.08 & 7.2 & 6.3 \\
10 & Apr. 16, 2006 & $6: 40$ & 22.86 & 121.30 & 17.9 & 6.2 \\
11 & Jul. 28, 2006 & $15: 40$ & 23.97 & 122.66 & 28 & 6.1 \\
12 & Aug. 28, 2006 & $1: 11$ & 24.80 & 123.07 & 135.3 & 6.1 \\
13 & Oct. 9 2006 & $18: 01$ & 20.70 & 119.83 & 28.0 & 6.1 \\
14 & Oct. 9 2006 & $19: 08$ & 20.77 & 119.93 & 8.0 & 6.1 \\
15 & Oct. 11 2006 & $14: 43$ & 20.89 & 119.90 & 10.0 & 6.0 \\
16 & Dec. 26, 2006 & $20: 26$ & 21.94 & 120.56 & 44.1 & 6.7 \\
17 & Dec. 26, 2006 & $20: 34$ & 21.95 & 120.39 & 47.0 & 6.4 \\
\hline * Date and Time are expressed in GMT. & & \\
** Mw: Moment magnitude & \multicolumn{5}{c}{}
\end{tabular}

rainfall effects are hard to avoid. An analysis of well water level data with barometric pressure data by BAYTAP-G (Tamura et al., 1991), a tidal analysis program, reveals barometric and tidal responses of the well water level. The barometric response is an indicator of the confinement of well water: if the well water level is independent of sea level, that is to say, the aquifer of the well is not connected to the sea, the tidal response of the well water level is an indicator of strain sensitivity. We compared the change in tidal water level to a theoretical tidal volumetric strain calculated from GOTIC 2 (Matsumoto et al., 2001), which calculates the theoretical earth and ocean tides, and estimated the strain sensitivity of the well water level. Finally, we checked 
whether there were any earthquake-related well water level changes. Using this step-wise procedure, by 2005 we had finally selected 12 wells from among the 550 wells of the WRA for our investigation of earthquake-related groundwater changes. We also constructed four new wells, thereby establishing a network of 16 wells in total. Each of these wells has only one screen, with the depths of the screens ranging from 80 to $252 \mathrm{~m}$. Groundwater level and background information, such as atmospheric temperature, atmospheric pressure, and rainfall, are collected at all wells, while groundwater temperature and radon concentration are collected at only some of the wells and are recorded at 2min intervals. The data are automatically sent to the Disaster Prevention Research Center (DPRC) at National ChengKung University. The accuracy of the water level data for the 16 wells is $2 \mathrm{~mm}$ according to the manufacturer of the water level meter. The resolution is estimated to be about $0.2 \mathrm{~mm}$, based on actual observation.

\subsection{Geological condition of the observation wells}

For the period November 2003 to December 2006, observations for more than 3 years were available for six of the 16 wells (Table 2). Hydrological conductivities for the six wells are relatively high (Table 2). The geological conditions of these six observation wells are discussed in the following sections.

2.3.1 Jhuangwei (JHU) The Jhuangwei observation well is located in Ilan County, northeastern Taiwan. The well was chosen because of its good confinement and its clear coseismic step-like change of 96-cm amplitude in response to the 1999 Chi-Chi earthquake. The location of JHU is also close to the Ilan seismic zone, which is the western extent of Okinawa trough (Fig. 1). The observations at JHU are expected to cover the area across the active block of the northern Taiwan seismic zone. We also expect that groundwater changes at JHU are related to seismic events in the southern tip of the Okinawa Trough. The observations at JHU may also provide some information related to crustal deformation in the active collision zone of the plate boundary. Based on borehole data, the geology at JHU is mostly composed of thin-bedded fine-grained silt and mud.

2.3.2 Hulien (HUL) The Hulien observation well in eastern Taiwan is located at the Hulien meteorological observation station, which is administered by the Central Weather Bureau (CWB), Taiwan. The HUL well is located on the trace of the surface rupture caused by the 1951 Hulien Earthquake, whose magnitude $\left(M_{\mathrm{L}}\right)$ was 7.1. HUL was chosen for monitoring large earthquakes in the eastern Taiwan seismic zone. CWB carries out geodetic, seismological, and meteorological observations, as well as GPS, at the same location. These integrated observations will provide information on the relationship between the groundwater level and the crustal deformation related to seismic events. The geology of HUL is mostly composed of thick calcareous sandstone and conglomerates with good cementation.

2.3.3 Tonlou (TLO) The Tonlou observation well is located in Miaoli County, central Taiwan. This well is situated on the axis of the Tonlou syncline and is close to the northern extent of Sanyi Fault (Central Geological Survey, 2000). The Hsinchu earthquake $\left(M_{\mathrm{w}} 7.1\right)$, which struck
Table 2. List of the six observation wells.

\begin{tabular}{|c|c|c|c|c|c|}
\hline \multirow{2}{*}{ Name } & \multicolumn{2}{|c|}{ Location } & \multirow{2}{*}{$\begin{array}{l}\text { Depth of the screen } \\
(\mathrm{m})\end{array}$} & \multirow{2}{*}{ Geology* } & \multirow{2}{*}{$\begin{array}{l}\text { Hydrological } \\
\text { Conductivity } \\
(\mathrm{cm} / \mathrm{s})\end{array}$} \\
\hline & Lon. & Lat. & & & \\
\hline JHU & 121.782 & 24.746 & $112-124$ & Qs,Qm & $3.70 \mathrm{E}-04$ \\
\hline HUL & 121.605 & 23.977 & $140-160$ & Qc & - \\
\hline TLO & 120.784 & 24.491 & $84-93$ & Qs & $1.33 \mathrm{E}-03$ \\
\hline DHR & 120.561 & 23.688 & $222-252$ & Qg & $6.92 \mathrm{E}-03$ \\
\hline LUC & 120.342 & 23.227 & $204-222$ & Qs, Qm & $4.45 \mathrm{E}-03$ \\
\hline NBA & 120.34 & 23.071 & $135-147$ & Qs,Qm & $3.07 \mathrm{E}-03$ \\
\hline
\end{tabular}

Hsinchu City in 1935, resulted in a surface earthquake fault, and the TLO well is near this fault. The Sanyi Fault is the northern extent of the 1999 Chi-Chi earthquake fault or the Chelungpu Fault (Fig. 1). Since the rupture ended in the Sanyi Fault, the northern segment seems to have some potential for earthquakes in the near future. In addition, the Sanyi Fault is close to the active Sanyi-Puli seismic zone. Data on this observation well are expected to enable the detection of groundwater level changes related to the local seismic activity.

2.3.4 Donher (DHR) The Donher groundwater observation well is located in Yunlin County, central Taiwan and situated in the Choushuishi alluvial fan. The DHR well was chosen for two reasons. First, it is close to the south end of the Chelungpu Fault (Fig. 1) and, second, it is sensitive to local seismic events. Therefore, observations at DHR are expected to cover the area in and around the south part of the Chelungpu Fault and the Tainan-Chiayi seismic zone. Since new seismic events are possible in the southern tip of Chelungpu Fault, data on the DHR well are important. The geology of DHR is mostly composed of thin-bedded fine-grained silt and mud, which are Holocene alluvial sediments.

2.3.5 Lauchia (LUC) The Lauchia observation well is located in Tainan County, southern Taiwan. LUC was chosen for its good confinement and because it showed a clear coseismic step-like 55-cm amplitude change in response to the 1999 Chi-Chi earthquake. The LUC well is locaed close to the Lauchia Fault (Central Geological Survey, 2000) and the Chiayi-Tainan seismic zone. The geology of LUC is mostly composed of thick layers of mudstone and thin layers of fine-grained silt.

2.3.6 Naba (NBA) The Naba observation well is located in Tainan County, southern Taiwan. NBA was chosen for its structural condition and good confinement. The well is located on the trace of the Hsinhua Fault (Central Geological Survey, 2000), which was the surface earthquake fault in the 1946 hazardous Hsinhua Earthquake $\left(M_{\mathrm{L}} 6.1\right)$. This fault belongs to the Chiayi-Tainan seismic zone. The geological units of the Naba observation well are mostly composed of thick layers of sandstone and siltstone with interbedded shale.

\section{Observation Results of the Groundwater Level 3.1 Usual groundwater level changes during the period from November 2003 to December 2006}

The groundwater level data at JHU shows repeated changes in groundwater level with a periodicity of 1-2 
(a)

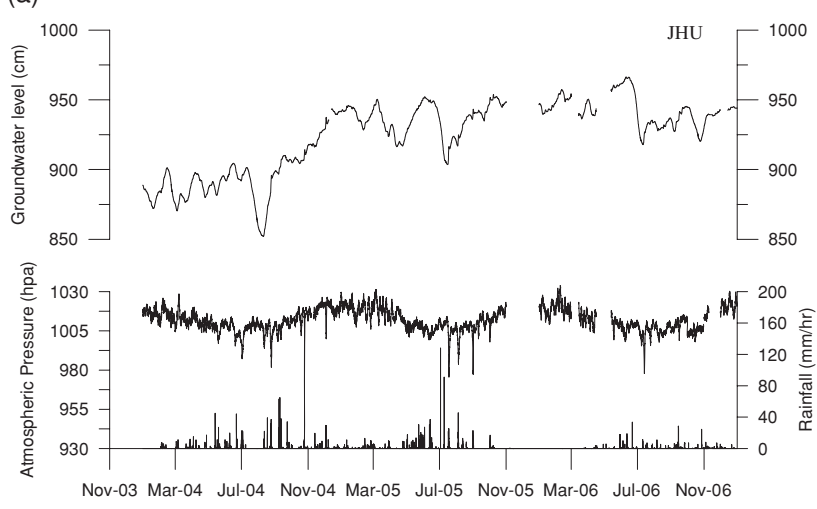

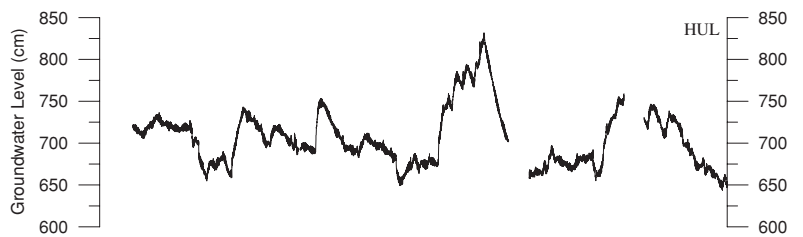

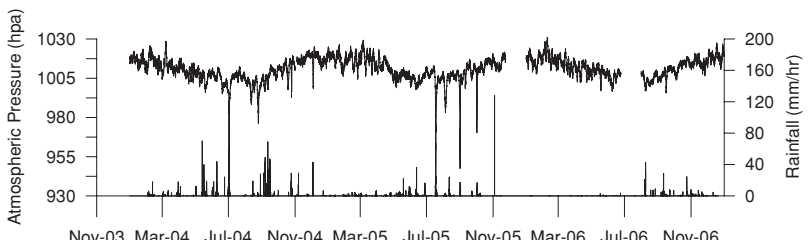

(b)
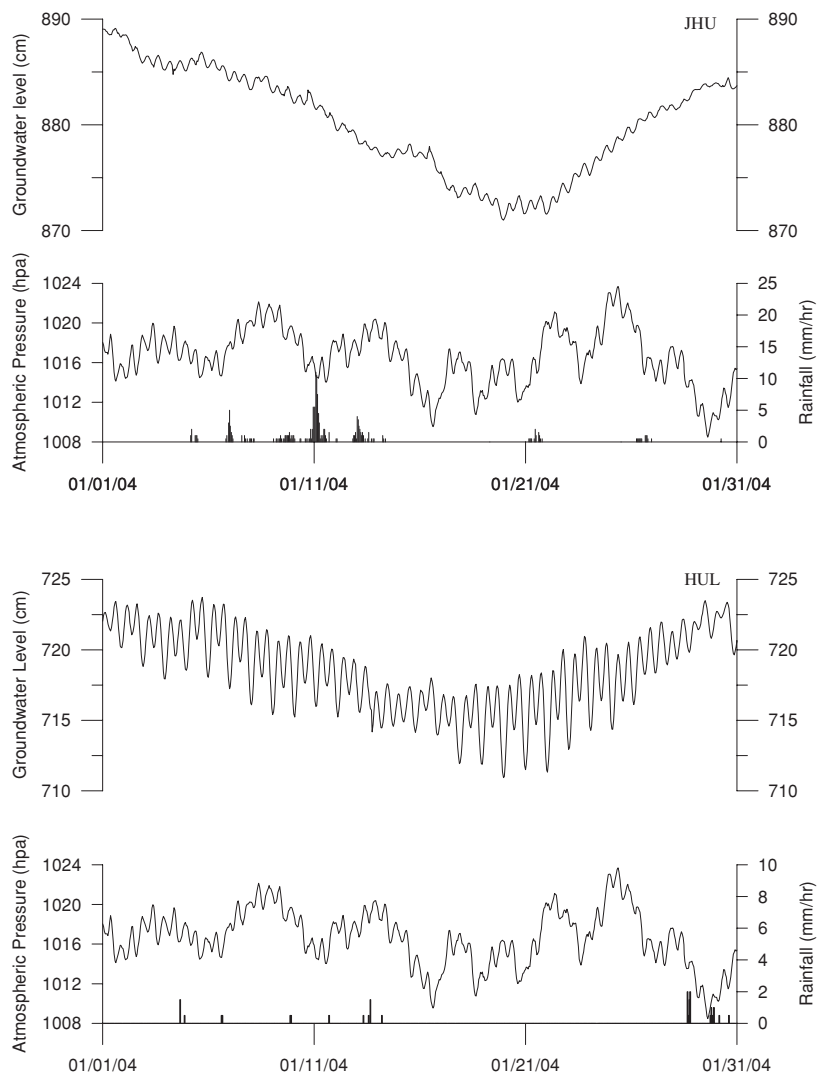

Fig. 2. Observation results at JHU and HUL. The data are hourly. (a) December 2003-December 2006, (b) January, 2004. (a)
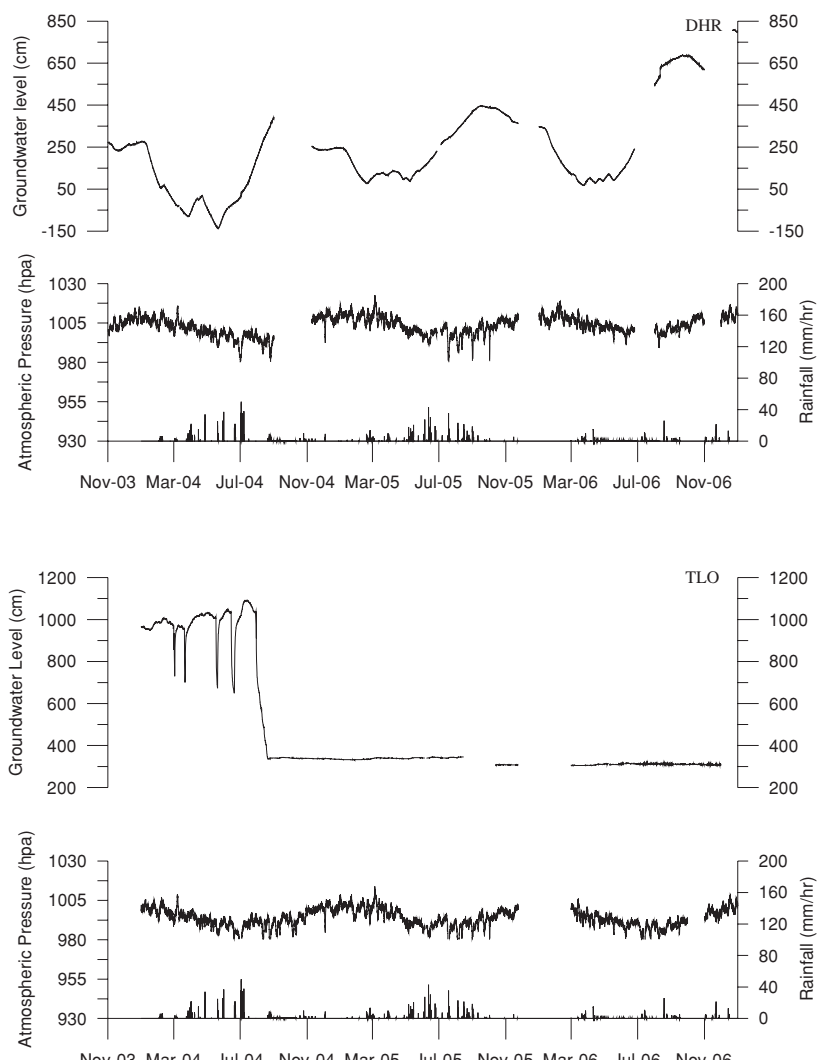

(b)
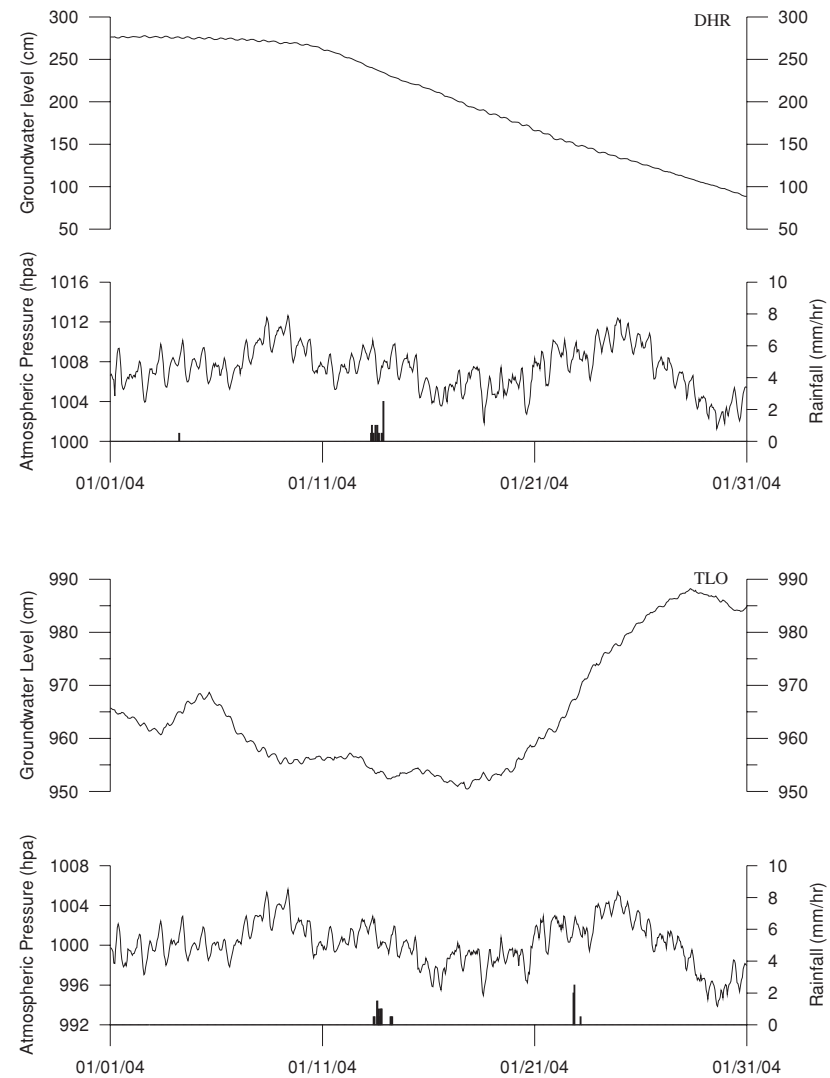

Fig. 3. Observation results at DHR and TLO. The data are hourly. (a) December 2003-December 2006, (b) January, 2004. 
(a)
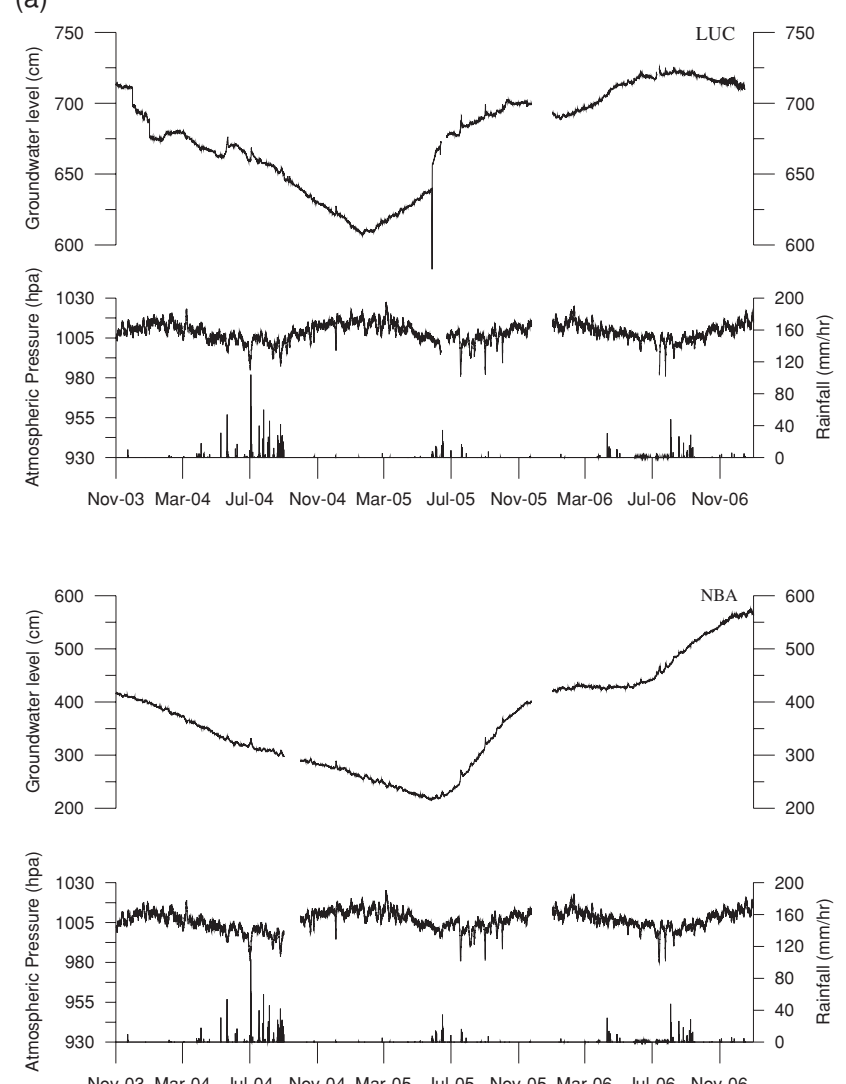

(b)
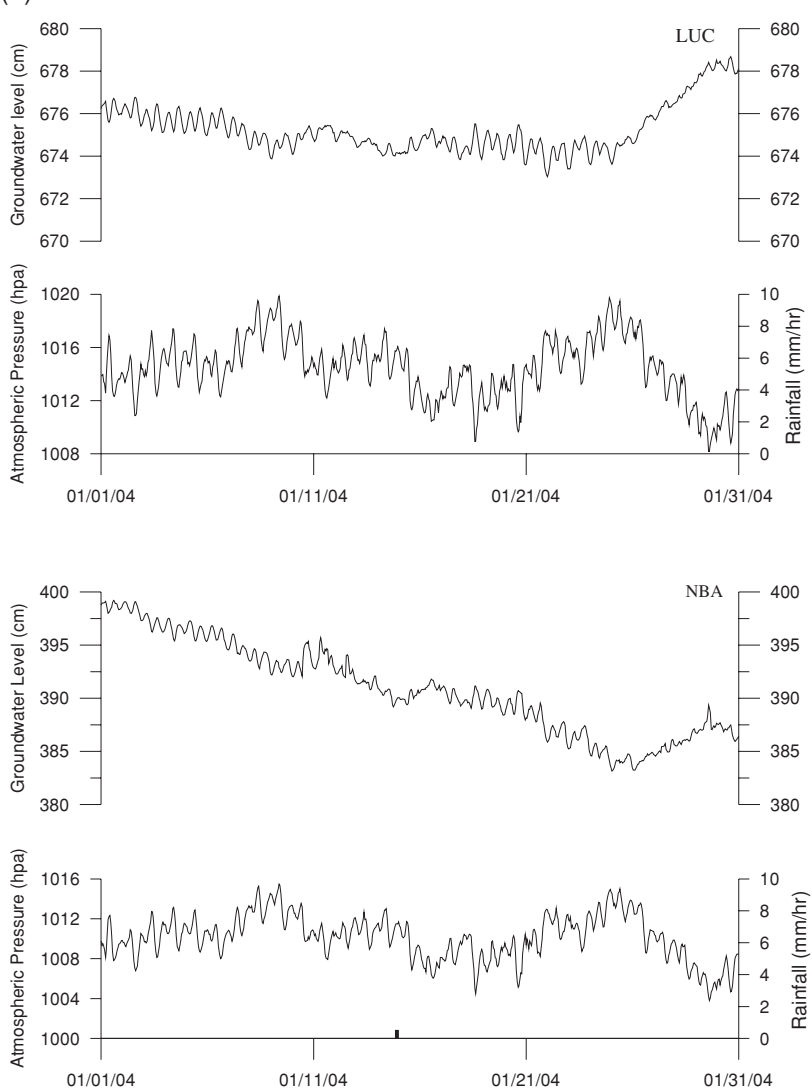

Fig. 4. Observation results at LUC and NBA. The data are hourly. (a) December 2003-December 2006, (b) January, 2004. months (Fig. 2(a)). The reason for these changes is currently unknown. The data also show barometric and tidal responses (Fig. 2(b)). The short-term rainfall effect on the groundwater level seems to last several days. The groundwater level at HUL shows a smooth trend with a clear association with tidal changes (Fig. 2(a) and (b)). The amplitude of the tide is about $4 \mathrm{~cm}$. A comparison of the groundwater level with the sea level near the well shows that tidal effects in the groundwater level are caused mainly by loading of the ocean tide. The ratio of the groundwater tide amplitude to that of the ocean tide is approximately 0.07 , and the time lag is about $1 \mathrm{~h}$. Heavy rainfall seems to create a long-term effect on the groundwater level that lasts for 1-2 months. The groundwater level at TLO has large artificial disturbances (Fig. 3(a)) as well as barometric and tidal responses. The short-term rainfall effect seems to last a few days. In August 2004, the water level measured at TLO fell drastically, and it has remained low since then. The reason for this change is currently unknown, but it may indicate that the observation system is experiencing some difficulties. Consequently, we do not use the data at TLO collected after August 2004 in our analysis. The groundwater level at DHR shows a smooth seasonal change with periodic tidal responses (Fig. 3(a) and (b)). The barometric pressure also has a small effect on the groundwater level. Seasonal changes seem to be caused by the long-term rainfall effect. The groundwater level at LUC shows a smooth trend with tidal changes and barometric responses (Fig. 4(a) and (b)). The groundwater level at NBA also shows a smooth trend with tidal and barometric responses. The long-term rainfall effect is not clear (Fig. 4(a) and (b)).

3.2 Tidal responses and sensitivities of groundwater levels to volumetric strain changes

As mentioned above, we used the BAYTAP-G program (Tamura et al., 1991) to estimate the responses of groundwater levels at the observations wells to tidal changes during the period from November 2003 until May 2004. There was relatively little rainfall during the entire observation period. The amplitudes and the phase shifts of the two main tidal components, $\mathrm{M}_{2}$ (period: $12.4 \mathrm{~h}$ ) and $\mathrm{O}_{1}$ (period: $25.8 \mathrm{~h}$ ), are considered to be indicators of tidal responses. Theoretical tidal volumetric strains at the observation wells were estimated from the GOTIC 2 program (Matsumoto et al., 2001). Using these results, we then estimated the phase shift of groundwater levels from the tidal volumetric strains and the strain sensitivities of groundwater levels to the volumetric strain changes (Table 3). In general, groundwater level is considered to rise when the aquifer contracts or the volumetric strain decreases. In such a case, in our study we set the phase shift to $0^{\circ}$ - and not to $180^{\circ}$ (Table 3 ) - in order to express the phase differences between the groundwater levels and volumetric strains more clearly. Table 3 shows the amplitudes of the strain sensitivities ranging from $0.1-$ $0.5 \mathrm{~mm} / \mathrm{e}-9$, where e- $9=10^{-9}$. The phase shifts are around $0^{\circ}$ at all of the six wells, with the exception of HUL.

The tidal fluctuation of groundwater levels is usually induced by (1) tidal volumetric strain changes caused by the earth and ocean tides or (2) pressure connections between the aquifer and the sea. The second reason is why the aquifer should face the sea. Of the six well for which we 
Table 3. Strain sensitivity of groundwater level at the six wells.

\begin{tabular}{lcccccc}
\hline & JHU & HUL & TLO & DHR & LUC & NBA \\
\hline a) SS* for $\mathrm{M}_{2}$ & $0.38 \pm 0.03$ & $0.50 \pm 0.01$ & $0.11 \pm 0.02$ & $0.44 \pm 0.04$ & $0.18 \pm 0.04$ & $0.29 \pm 0.02$ \\
b) PD** for M2 & $63 \pm 21$ & $164 \pm 6$ & $54 \pm 49$ & $13 \pm 23$ & $6 \pm 34$ & $7 \pm 15$ \\
\hline c) SS for $\mathrm{O}_{1}$ & $0.44 \pm 0.12$ & $0.38 \pm 0.06$ & $0.27 \pm 0.14$ & $0.32 \pm 0.17$ & $0.18 \pm 0.07$ & $0.27 \pm 0.15$ \\
d) PD for O1 & $-22 \pm 90$ & $-146 \pm 61$ & $22 \pm 67$ & $17 \pm 41$ & $-1 \pm 73$ & $-4 \pm 46$ \\
\hline Mean SS: (a+c)/2 & $0.41 \pm 0.08$ & $0.44 \pm 0.04$ & $0.19 \pm 0.08$ & $0.38 \pm 0.11$ & $0.18 \pm 0.06$ & $0.28 \pm 0.09$ \\
\hline *SS: Strain Sensitivity (mm/10 & & & & & \\
**PD: Phase Difference of the groundwater level from the theoretical tidal volumetric strain (degree)
\end{tabular}

have useable data, only HUL is located in the coastal region (Fig. 1). The phase shifts in Table 3 and the locations of the wells show that tidal responses in the observed groundwater levels are likely to be caused by volumetric strain changes at all of the six wells, with the exception of HUL. At HUL, as mentioned above, tidal groundwater level changes seem to be strongly related to the ocean tide; consequently, pressure connections may make a major contribution to tidal changes there. It is also possible that volumetric strain changes caused by ocean tides were not precisely calculated at HUL. For these reasons, the strain sensitivity at HUL in Table 3 is less reliable than that at the other wells.

\subsection{Coseismic and/or postseismic groundwater level changes}

Between November 2003 and December 2006, there were 17 earthquakes in and around Taiwan with a magnitudes $\geq 6$ (Table 1, Fig. 1). We checked the groundwater level changes at the six observation wells before and after these each of these 17 earthquakes.

Figure 5 shows coseismic and/or postseismic groundwater level changes at all six observation wells related to the Taitung earthquake $\left(M_{\mathrm{w}} 6.6\right)$ on December 10, 2003 (No. 1 earthquake in Table 1 and Fig. 1). The patterns of the groundwater level changes are different, and we classified these into three patterns: persistent change $(\mathrm{P})$, oscillation $(\mathrm{O})$, and no change (N) (Fig. 5, Table 4). Persistent changes include step-like changes and trend changes that occur just after the earthquake (Fig. 5). Sometimes they exhibit oscillations; in these cases, we denote them 'O+P' (Fig. 5). Table 4 shows the patterns of the groundwater level changes related to the 17 earthquakes.

\section{Discussion}

Earthquakes cause ground shaking and static crustal deformation, which has led to the theory that these events cause earthquake-related groundwater changes. According to the poroelastic theory (Biot, 1941; Roeloffs, 1996), stress, strain, pore pressure, and water content are related to each other. Based on these relationships, Montgomery and Manga (2003) pointed out that there are two main causes of earthquake-related groundwater changes: static volumetric strain change and ground shaking, with the latter including dynamic volumetric strain change.

There have been only a few published reports on studies that have evaluated observed coseismic and/or post-

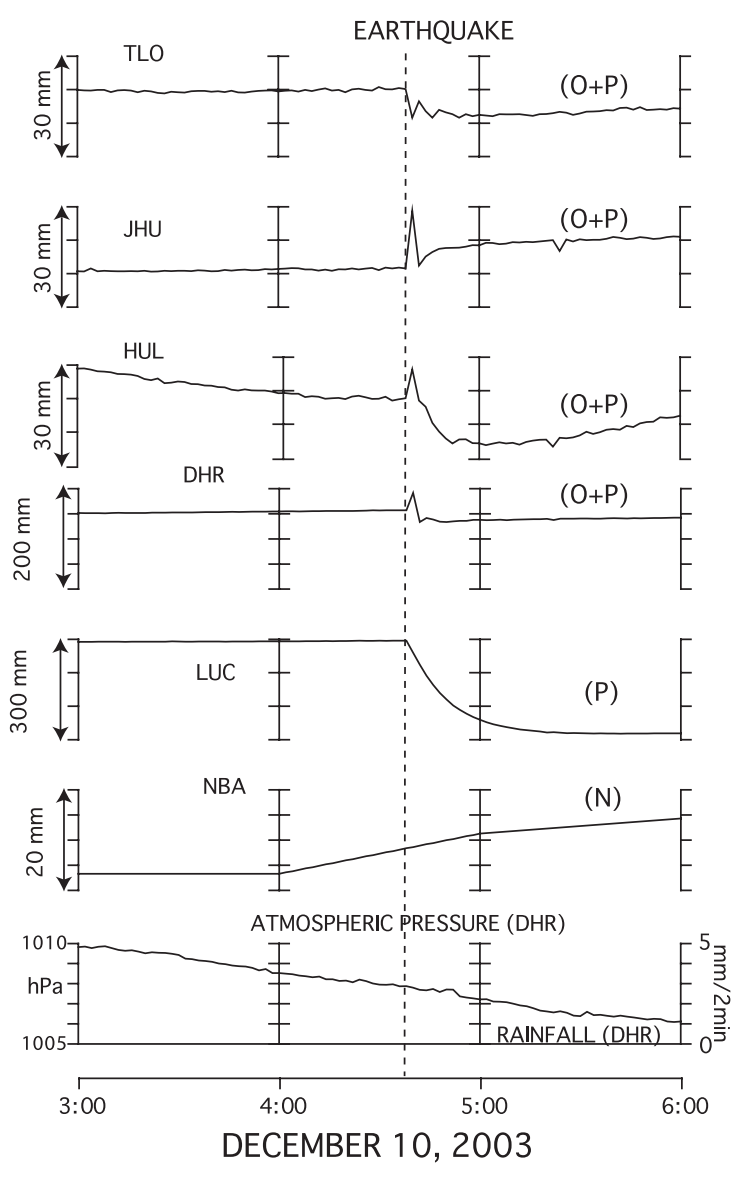

Fig. 5. Coseismic and/or postseismic groundwater level changes associated with the earthquake that occurred on December 10, 2003, or No. 1 earthquake in Table 1. Two-minute values are shown in the graph. The date and time are in GMT. ' $\mathrm{P}$ ', ' $\mathrm{O}+\mathrm{P}$ ' and ' $\mathrm{N}$ ' are defined in the text.

seismic groundwater changes in association with static volumetric strain changes and ground shaking using observed data, primarily because it is usually difficult to obtain both precise groundwater data and ground shaking data at the same locations. In Taiwan, we obtained both data sets from our groundwater observation wells and the dense network of three-component accelerators, as mentioned above. Figures 6-11 show the relationships among coseismic and/or postseismic groundwater level changes, coseismic static volumetric strain changes, and the peak ground acceleration (PGA) at each of the six wells. The coseismic static volumetric strain changes at each of the 
Table 4. (a) List of the coseismic and/or postseismic groundwater level changes at JHU, HUL, and TLO. At TLO only the data from December 2003 to July 2004 were analyzed. "e-9" means $10^{-9}$ strain. (b) List of the coseismic and/or postseismic groundwater level changes at DHR, LUC, and NBA.

(a)

\begin{tabular}{|c|c|c|c|c|c|c|c|c|c|c|c|c|c|c|c|}
\hline \multirow[b]{2}{*}{ No.*1 } & \multicolumn{5}{|c|}{$\mathrm{JHU}\left(\mathrm{SS}(* 2)=0.41 \mathrm{~mm} / \mathrm{e}^{-9}\right)$} & \multicolumn{5}{|c|}{$\mathrm{HUL}\left(\mathrm{SS}=0.44 \mathrm{~mm} / \mathrm{e}^{-9}\right)$} & \multicolumn{5}{|c|}{ TLO (SS $\left.=0.19 \mathrm{~mm} / \mathrm{e}^{-9}\right)$} \\
\hline & $\begin{array}{c}\mathrm{Glo}(* 3) \\
(\mathrm{mm})\end{array}$ & Type & Vol.Str. $(* 4)$ & $\begin{array}{c}\mathrm{Gle}(* 5) \\
(\mathrm{mm})\end{array}$ & $\begin{array}{l}\text { PGA } \\
\text { (gal) }\end{array}$ & $\begin{array}{l}\text { GLo } \\
(\mathrm{mm})\end{array}$ & Type & Vol.Str. & $\begin{array}{c}\text { GLe } \\
(\mathrm{mm})\end{array}$ & $\begin{array}{l}\text { PGA } \\
\text { (gal) }\end{array}$ & $\begin{array}{c}\text { GLo } \\
(\mathrm{mm})\end{array}$ & Type & Vol.Str. & $\begin{array}{c}\text { GLe } \\
(\mathrm{mm})\end{array}$ & $\begin{array}{l}\text { PGA } \\
\text { (gal) }\end{array}$ \\
\hline 1 & 11.2 & $\mathrm{O}+\mathrm{P}$ & $-5.89 \mathrm{E}-10$ & 0.24 & 6 & -13.5 & $\mathrm{O}+\mathrm{P}$ & $-3.84 \mathrm{E}-09$ & 1.69 & 29 & -8.6 & $\mathrm{O}+\mathrm{P}$ & $2.66 \mathrm{E}-10$ & -0.05 & 11 \\
\hline 2 & & $\mathrm{O}$ & $-5.41 \mathrm{E}-12$ & 0.00 & 6 & & 0 & $9.28 \mathrm{E}-11$ & -0.04 & 29 & & 0 & $1.26 \mathrm{E}-11$ & 0.00 & 4 \\
\hline 3 & & $\mathrm{~N}$ & $-1.06 \mathrm{E}-11$ & 0.00 & 8 & & $\mathrm{O}$ & $2.54 \mathrm{E}-11$ & -0.01 & 13 & & $\mathrm{~N}$ & $1.92 \mathrm{E}-11$ & 0.00 & 3 \\
\hline 4 & -9.2 & $\mathrm{O}+\mathrm{P}$ & $-1.51 \mathrm{E}-10$ & 0.06 & 4 & 3.2 & $\mathrm{P}$ & $-6.58 \mathrm{E}-10$ & 0.29 & 13 & 3.9 & $\mathrm{P}$ & $-9.30 \mathrm{E}-11$ & 0.02 & 7 \\
\hline 5 & -12.9 & $\mathrm{O}+\mathrm{P}$ & $-3.47 \mathrm{E}-10$ & 0.14 & 70 & & 0 & $-2.38 \mathrm{E}-09$ & 1.05 & 53 & - & - & - & - & - \\
\hline 6 & 15.9 & $\mathrm{O}+\mathrm{P}$ & $-9.76 \mathrm{E}-10$ & 0.40 & 38 & 2.4 & $P$ & $2.27 \mathrm{E}-10$ & -0.10 & 14 & - & - & - & - & - \\
\hline 7 & -12.3 & $\mathrm{P}$ & $4.76 \mathrm{E}-10$ & -0.20 & 14 & & 0 & $-2.27 \mathrm{E}-10$ & 0.10 & 9 & - & - & - & - & - \\
\hline 8 & -5.7 & $P$ & $2.09 \mathrm{E}-10$ & -0.09 & 12 & & 0 & $2.09 \mathrm{E}-10$ & -0.09 & 18 & - & - & - & - & - \\
\hline 9 & -7.0 & $\mathrm{P}$ & $-1.46 \mathrm{E}-10$ & 0.06 & 5 & & 0 & $-8.35 E-10$ & 0.37 & 5 & - & - & - & - & - \\
\hline 10 & -5.8 & $\mathrm{O}+\mathrm{P}$ & $-5.09 \mathrm{E}-11$ & 0.02 & 4 & & 0 & $-2.69 \mathrm{E}-10$ & 0.12 & 11 & - & - & - & - & - \\
\hline 11 & -19.6 & $\mathrm{P}$ & $1.72 \mathrm{E}-11$ & -0.01 & 31 & & $\mathrm{~N}$ & $-5.05 E-11$ & 0.02 & 8 & - & - & - & - & - \\
\hline 12 & & $\mathrm{~N}$ & $-6.71 \mathrm{E}-12$ & 0.00 & 4 & & 0 & $-1.64 \mathrm{E}-12$ & 0.00 & 11 & - & - & - & - & - \\
\hline 13 & & $\mathrm{~N}$ & $-2.68 \mathrm{E}-12$ & 0.00 & 2 & & $\mathrm{~N}$ & $9.29 \mathrm{E}-12$ & 0.00 & 4 & - & - & - & - & - \\
\hline 14 & & $\mathrm{~N}$ & $-1.15 \mathrm{E}-12$ & 0.00 & 2 & & $\mathrm{~N}$ & $-1.30 \mathrm{E}-12$ & 0.00 & 4 & - & - & - & - & - \\
\hline 15 & & $\mathrm{~N}$ & $-5.06 \mathrm{E}-12$ & 0.00 & 4 & & $\mathrm{~N}$ & $-9.94 \mathrm{E}-12$ & 0.00 & 7 & - & - & - & - & - \\
\hline 16 & -2.1 & $P$ & $-9.60 E-10$ & 0.39 & 6 & & 0 & $-2.39 \mathrm{E}-09$ & 1.05 & 15 & - & - & - & - & - \\
\hline 17 & -6.9 & $\mathrm{P}$ & $-3.13 \mathrm{E}-10$ & 0.13 & 7 & & 0 & $-4.61 \mathrm{E}-10$ & 0.20 & 18 & - & - & - & - & - \\
\hline
\end{tabular}

*1 The number of the earthquakes in Table 1.

$* 2$ SS: Strain Sensitivity.

*3 Glo: Observed persistent groundwater level change.

*4 Vol.Str.: Calculated static coseismic volumetric strain change.

*5 Gle: Expected groundwater level change: (Vol.Str)*SS.

(b)

\begin{tabular}{|c|c|c|c|c|c|c|c|c|c|c|c|c|c|c|c|}
\hline \multirow[b]{2}{*}{ No. } & \multicolumn{5}{|c|}{ DHR (SS $\left.=0.38 \mathrm{~mm} / \mathrm{e}^{-9}\right)$} & \multicolumn{5}{|c|}{ LUC (SS=0.18 mm/e-9) } & \multicolumn{5}{|c|}{ NBA $\left(S S=0.28 \mathrm{~mm} / \mathrm{e}^{-9}\right)$} \\
\hline & $\begin{array}{c}\text { GLo } \\
(\mathrm{mm})\end{array}$ & Type & Vol.Str. & $\begin{array}{c}\text { GLe } \\
(\mathrm{mm})\end{array}$ & $\begin{array}{l}\text { PGA } \\
\text { (gal) }\end{array}$ & $\begin{array}{c}\text { GLo } \\
(\mathrm{mm}) \\
\end{array}$ & Type & Vol.Str. & $\begin{array}{c}\text { GLe } \\
(\mathrm{mm})\end{array}$ & $\begin{array}{l}\text { PGA } \\
\text { (gal) }\end{array}$ & $\begin{array}{c}\text { GLo } \\
(\mathrm{mm})\end{array}$ & Type & Vol.Str. & $\begin{array}{c}\mathrm{GLe} \\
(\mathrm{mm})\end{array}$ & $\begin{array}{l}\text { PGA } \\
\text { (gal) }\end{array}$ \\
\hline 1 & -23.5 & $\mathrm{O}+\mathrm{P}$ & 7.91E-09 & -3.01 & 27 & -275.7 & $\mathrm{P}$ & $1.16 \mathrm{E}-08$ & -2.09 & 17 & & $\mathrm{~N}$ & $1.09 \mathrm{E}-08$ & -3.05 & 11 \\
\hline 2 & & $\mathrm{~N}$ & $-2.77 \mathrm{E}-15$ & 0.00 & 2 & & $\mathrm{~N}$ & $1.77 \mathrm{E}-11$ & 0.00 & 3 & & $\mathrm{~N}$ & $1.52 \mathrm{E}-11$ & 0.00 & 8 \\
\hline 3 & & $\mathrm{~N}$ & $-1.02 \mathrm{E}-14$ & 0.00 & 2 & 0.9 & $\mathrm{P}$ & $3.16 \mathrm{E}-11$ & -0.01 & 4 & & $\mathrm{~N}$ & $2.51 \mathrm{E}-11$ & -0.01 & 6 \\
\hline 4 & 18.2 & $P$ & $1.50 \mathrm{E}-10$ & -0.06 & 19 & -0.5 & $\mathrm{P}$ & $9.01 \mathrm{E}-10$ & -0.16 & 10 & & $\mathrm{~N}$ & $1.20 \mathrm{E}-09$ & -0.34 & 16 \\
\hline 5 & 0.3 & $P$ & $-1.50 \mathrm{E}-09$ & 0.57 & 20 & & 0 & $-4.01 \mathrm{E}-10$ & 0.07 & 17 & & $\mathrm{~N}$ & $-3.71 \mathrm{E}-10$ & 0.10 & 4 \\
\hline 6 & & $\mathrm{~N}$ & $5.54 \mathrm{E}-10$ & -0.21 & 10 & & 0 & $2.23 \mathrm{E}-11$ & 0.00 & 5 & & 0 & $6.68 \mathrm{E}-11$ & -0.02 & 5 \\
\hline 7 & & $\mathrm{~N}$ & $-3.36 \mathrm{E}-11$ & 0.01 & 5 & & 0 & $-4.11 \mathrm{E}-11$ & 0.01 & 6 & & $\mathrm{~N}$ & $3.77 \mathrm{E}-11$ & -0.01 & 6 \\
\hline 8 & & $\mathrm{~N}$ & $-1.78 \mathrm{E}-11$ & 0.01 & 5 & & $\mathrm{~N}$ & $6.11 \mathrm{E}-12$ & 0.00 & 5 & & $\mathrm{~N}$ & $1.08 \mathrm{E}-11$ & 0.00 & 4 \\
\hline 9 & & $\mathrm{~N}$ & $3.20 \mathrm{E}-09$ & -1.22 & 5 & 7.8 & $\mathrm{O}+\mathrm{P}$ & 4.19E-09 & -0.75 & 18 & & $\mathrm{~N}$ & $2.63 \mathrm{E}-09$ & -0.74 & 10 \\
\hline 10 & & $\mathrm{~N}$ & $7.79 \mathrm{E}-11$ & -0.03 & 7 & & $\mathrm{~N}$ & $4.71 \mathrm{E}-10$ & -0.08 & 3 & & $\mathrm{~N}$ & $5.91 \mathrm{E}-10$ & -0.17 & 6 \\
\hline 11 & & $\mathrm{~N}$ & $-9.82 \mathrm{E}-12$ & 0.00 & 5 & & $\mathrm{~N}$ & $-2.40 E-12$ & 0.00 & 3 & & $\mathrm{~N}$ & $-7.51 \mathrm{E}-13$ & 0.00 & 2 \\
\hline 12 & & $\mathrm{~N}$ & $-9.12 \mathrm{E}-12$ & 0.00 & 4 & & $\mathrm{~N}$ & $5.54 \mathrm{E}-12$ & 0.00 & 2 & & $\mathrm{~N}$ & $5.56 \mathrm{E}-11$ & -0.02 & 5 \\
\hline 13 & & $\mathrm{~N}$ & $2.12 \mathrm{E}-11$ & -0.01 & 4 & & $\mathrm{~N}$ & $4.38 \mathrm{E}-11$ & -0.01 & 6 & & $\mathrm{~N}$ & $5.04 \mathrm{E}-11$ & -0.01 & 7 \\
\hline 14 & & $\mathrm{~N}$ & $-8.93 \mathrm{E}-12$ & 0.00 & 2 & & $\mathrm{~N}$ & $-1.66 \mathrm{E}-11$ & 0.00 & 3 & & $\mathrm{~N}$ & $-2.00 \mathrm{E}-11$ & 0.01 & 5 \\
\hline 15 & & $\mathrm{~N}$ & $-1.12 \mathrm{E}-11$ & 0.00 & 2 & & $\mathrm{~N}$ & $-1.79 \mathrm{E}-11$ & 0.00 & 2 & & $\mathrm{~N}$ & $-2.27 \mathrm{E}-11$ & 0.01 & 4 \\
\hline 16 & & 0 & $-8.75 \mathrm{E}-10$ & 0.33 & 38 & & $\mathrm{~N}$ & $8.25 E-10$ & -0.15 & 45 & -12.2 & $\mathrm{O}+\mathrm{P}$ & $1.81 \mathrm{E}-09$ & -0.51 & 59 \\
\hline 17 & & $\mathrm{O}$ & 4.33E-10 & -0.16 & 58 & & $\mathrm{~N}$ & 4.55E-09 & -0.82 & 37 & -25.8 & $\mathrm{O}+\mathrm{P}$ & $7.74 \mathrm{E}-09$ & -2.17 & 106 \\
\hline
\end{tabular}

wells were calculated from the fault models of the 17 earthquakes (Broadband Array in Taiwan for Seismology, 2009) using Okada's program (1992). In our calculation, we assumed a homogeneous elastic half-space and used the point source models (Broadband Array in Taiwan for Seismology, 2009). The peak ground acceleration is estimated by interpolating observed data from the accelerator network. Since the strain sensitivities at the six wells range from 0.1 to $0.5 \mathrm{~mm} / \mathrm{e}-9$ (Table 3 ) and the resolution of the water level data is $0.2 \mathrm{~mm}$, the detection limit of the static volumetric strain change is about 1e-9 at the six wells. Actually, most of the static coseismic volumetric strain changes at the observation wells were smaller than 1e-9 (Table 4(a) and (b); Fig. 6-11).
Figures 6-11, which show the contributions of the static coseismic volumetric strain changes and peak ground accelerations to the coseismic and/or postseismic groundwater level changes, present data using a method modified from Itaba and Koizumi (2007). The direction and size of the triangle show the sign (rise or drop) and amplitude of the persistent groundwater level change, respectively. In addition, the color of the triangle shows how the groundwater level changes can be explained by the calculated static volumetric strain changes. This convention clearly shows the tendency of the coseismic and/or postseismic persistent groundwater level changes at each of the six wells.

There were many persistent changes at JHU (Fig. 6), and most were coseismic drops. The signs of these co- 


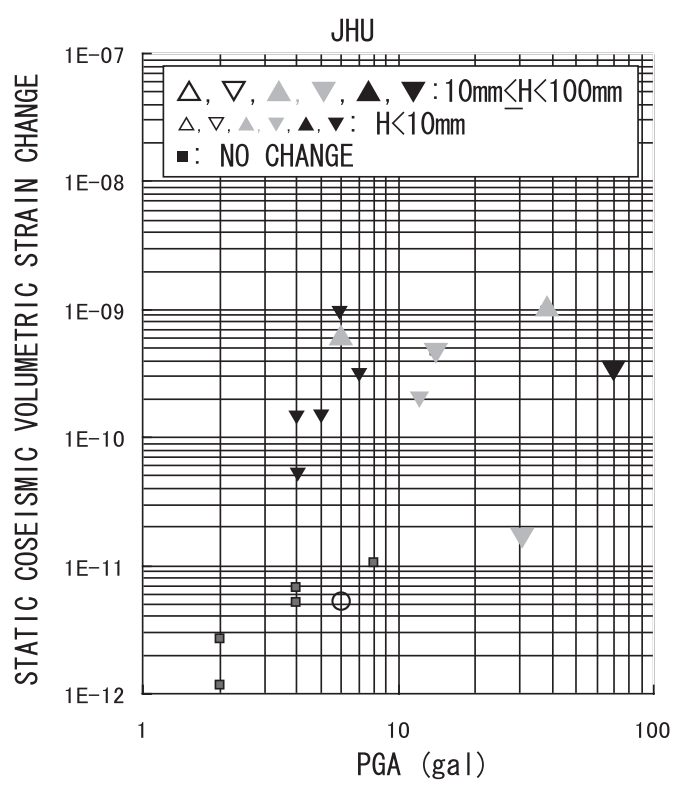

Fig. 6. Relationships among the coseismic and/or postseismic groundwater level changes, calculated coseismic static volumetric strain changes (CVSC), and peak ground accelerations (PGA) at JHU. Symbols show patterns of the coseismic and/or postseismic groundwater level changes. Triangles, circles, and squares show persistent changes, only oscillations, and no changes, respectively (Table 4(a)). The directions of the triangles show persistent increases or decreases in the groundwater level. The size of the triangle shows the amplitude $(H)$ of the persistent change. The triangle color shows how the persistent groundwater level change is explained by volumetric strain changes. 'White' means 'quantitatively explainable', 'gray' means 'qualitatively explainable', and 'black' means it is not explained by the volumetric strain change at all. 'Quantitatively explainable' means that observed coseismic and/or postseismic groundwater level changes are 50-200\% of the expected groundwater level changes (Gle) in Tables 4(a) and 4(b).

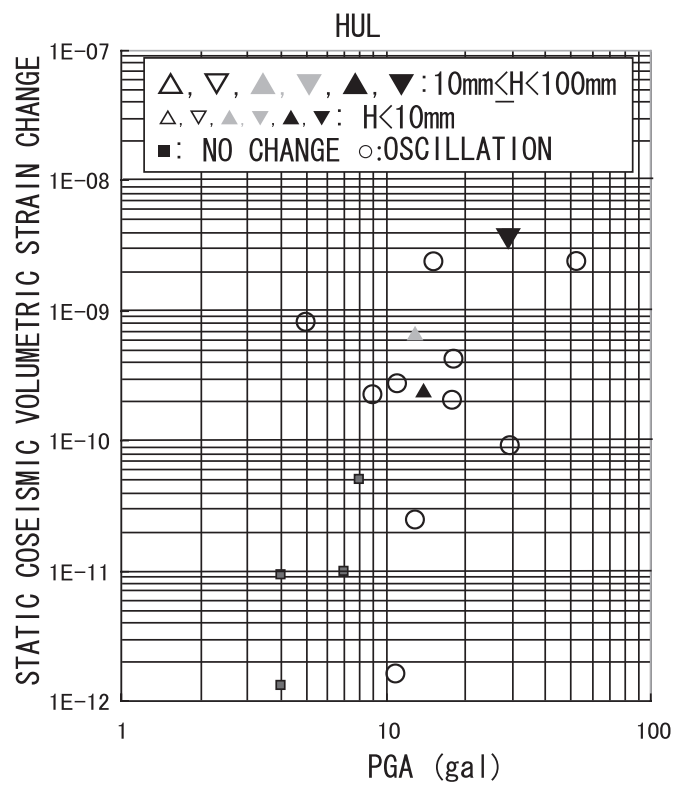

Fig. 7. Relationships among the coseismic and/or postseismic groundwater level changes, CVSC, and PGA at HUL.

seismic drops were not always explained by the signs of the static coseismic volumetric strain changes (CVSC). In addition, all of the calculated coseismic static volumetric strain changes (CVSC) were smaller than 1e-9 (Table 4(a)),

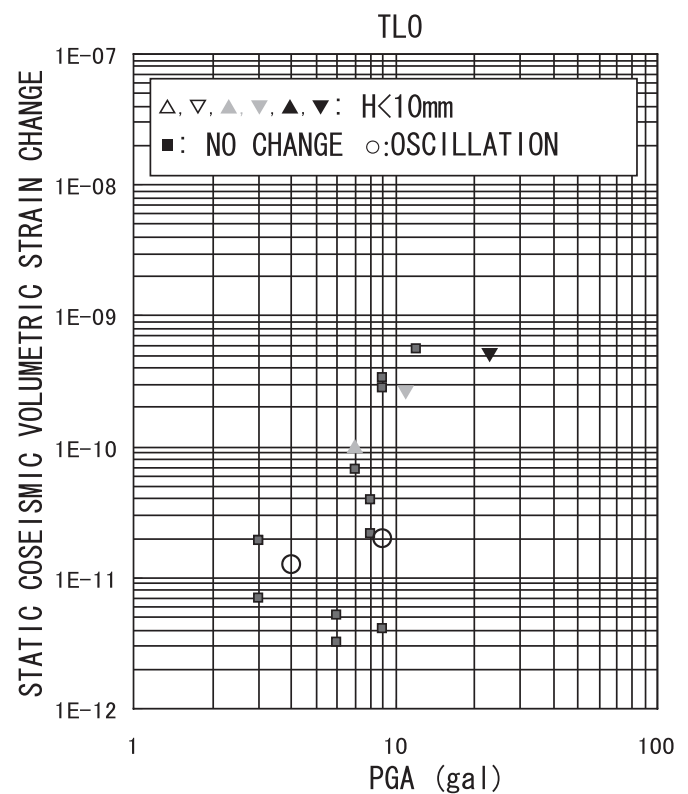

Fig. 8. Relationships among the coseismic and/or postseismic groundwater level changes, CVSC, and PGA at TLO. At TLO, only the data from December 2003 to July 2004 were analyzed.

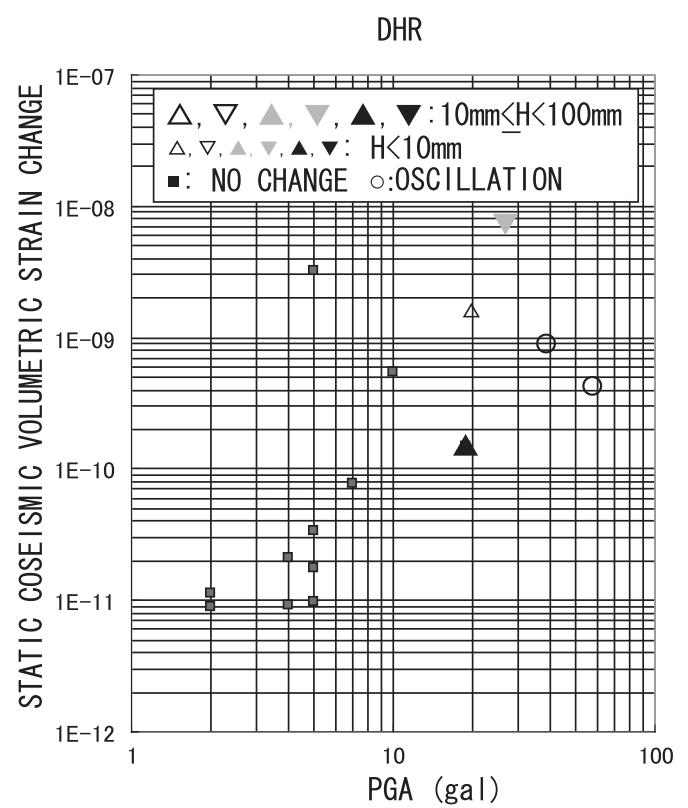

Fig. 9. Relationships among the coseismic and/or postseismic groundwater level changes, CVSC, and PGA at DHR.

and therefore too small to cause the observed persistent changes. As a result, we conclude that they were not due to CVSC. Ground shaking seems the main factor causing the persistent changes. However, when CVSC is $\leq 1 \mathrm{e}-11$, persistent changes are unlikely to occur. Many oscillations occurred at HUL (Fig. 7). There are also three persistent changes, although these cannot be explained by CVSC. Therefore, those oscillations and persistent changes are caused mainly by ground shaking. Oscillations or persistent changes always occurred when the PGA was $>10$ gal ( $\left.1 \mathrm{gal}=0.01 \mathrm{~m} / \mathrm{s}^{2}\right)$; however, even when the PGA was $<10$ gal, oscillations occurred when CVSC was $>1 \mathrm{e}-10$. 
LUC

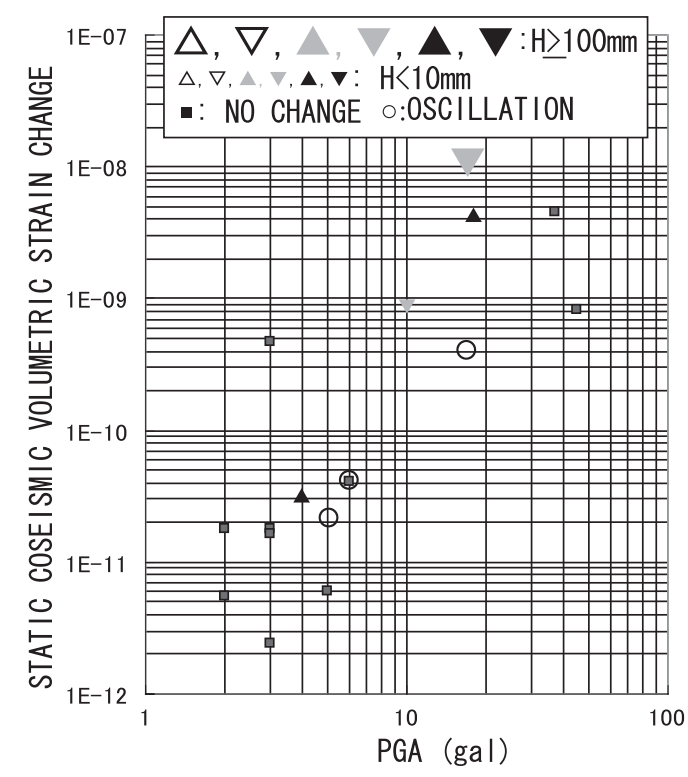

Fig. 10. Relationships among the coseismic and/or postseismic groundwater level changes, CVSC, and PGA at LUC.

NBA

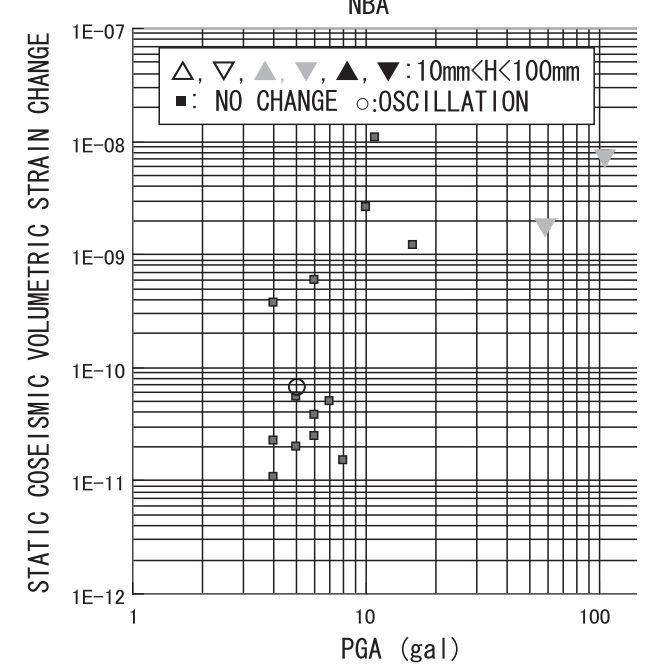

Fig. 11. Relationships among the coseismic and/or postseismic groundwater level changes, CVSC, and PGA at NBA.

CVSC and PGA were smaller at TLO than at the other five wells because TLO is farther from the epicenters of the 17 earthquakes than the other wells (Figs. 1 and 8). Two persistent changes were observed, but these cannot be explained by CVSC. Three persistent changes and two oscillations were observed at DHR (Fig. 9) when the PGA was $\geq 19$ gal (Table 4(b)). Two of the three persistent changes can not be explained by CVSC. When the PGA was $<10$ gal and the CVSC $<2 \mathrm{e}-11$, no coseismic changes occurred at LUC (Fig. 10). There were only two persistent changes at NBA (Fig. 11), and these occurred when the PGA was $>50$ gal.

On the whole, ground shaking seems the main reason for the earthquake-related changes at the six wells because the calculated static volumetric strain changes cannot sufficiently explain them. While the PGA can explain the persis- tent changes at NBA, it cannot always explain the changes at the other wells, especially at the sensitive wells, such as JHU, where there are many persistent coseismic and/or postseismic changes. This means there are factors other than the acceleration of ground shaking that causes coseismic and/or postseismic groundwater level changes. At JHU, persistent changes are likely to occur when the CVSC is $>1 \mathrm{e}-10$ even if the PGA is $<10$ gal. These changes can be caused by large distant earthquakes. Long-period seismic waves from those earthquakes can cause dynamic strain changes, that can, in turn, produce persistent changes. Brodsky et al. (2003) suggested a pore-cleaning effect of dynamic strain changes as a factor causing earthquakerelated persistent groundwater level changes.

As mentioned above, we assumed a homogeneous elastic half-space in our calculation of the coseismic static volumetric strain changes. This elastic half-space decreases the coseismic static volumetric strain changes in inverse proportion to the cubic of the hypocentral distance. Since most of the coseismic and/or postseismic groundwater level changes observed in our study were caused by relatively distant earthquakes (Fig. 1; Table 4), it seems natural that those static volumetric strain changes should scarcely have an effect on the earthquake-related changes (Itaba et al., $2008 \mathrm{a}, \mathrm{b})$. However, the actual crust is inhomogeneous, and it is known that observed coseismic strain changes are often different from those calculated in the same manner. The local strain accumulation due to inhomogeneous structures and its subsequent release by ground shaking is one possible explanation of the difference (Watanabe, 1991). This strain release, which is a type of static volumetric strain change due to the presence of inhomogeneous structures, is another possible causal factor of earthquake-related changes; ground shaking is also important in this context.

\section{Conclusions}

We have investigated groundwater level data collected between December 2003 and December 2006 at six groundwater observation network wells in Taiwan with the aim of assessing earthquake-related groundwater changes. The strain sensitivity of the groundwater level at the six wells ranged from $0.1-0.5 \mathrm{~mm} / \mathrm{e}-9$, which means that the groundwater level data at the six wells can detect strain changes of about 1e-9 or larger. We analyzed coseismic and/or postseismic groundwater level changes related to 17 earthquakes in and around Taiwan whose magnitudes were $\geq 6.0$. Our analysis revealed that ground shaking seems to be the major causal factor of earthquake-related changes in groundwater but that the acceleration of this ground shaking cannot always explain the observed groundwater level changes.

Acknowledgments. This paper was financially supported by grants from National Science Council and Water Resource Agency of Taiwan. We greatly thank Dr. Evelyn Roeloffs for her helpful advice. We also thank two anonymous reviewers for their helpful comments and advice.

\section{References}

Akita, F. and N. Matsumoto, Coseismic groundwater level changes in hot spring wells in Hokkaido induced by four earthquakes larger than M7.5 
between 1993 and 1994 Earthquake, Geophys. Res. Lett., 53, 193-204, 2001.

Biot, M. A., General theory of three-dimensional consolidation, J. Appl. Phys., 12, 155-164, 1941.

Broadband Array in Taiwan for Seismology (BATS), Centroid moment tensor (CMT) solutions, http://bats.earth.sinica.edu.tw/, 2009.

Brodsky, E., E. Roeloffs, D. Woodcock, I. Gall, and M. Manga, A mechanism for sustained groundwater pressure changes induced by distant earthquakes, J. Geophys. Res., 108(B8), 2390, doi:10. 1029/2002JB002321, 2003.

Carrigan, C. R., G. C. P. King, G. E. Barr, and N. E. Bixler, Potential for water table excursions induced by seismic events at Yucca Mountain, Nevada, Geology, 19, 1157-1160, 1991.

Central Geological Survey, Active Faults Map in Taiwan, 2000 (in Chinese).

Chang, C. P., T. Y. Chang, J. Angelier, H. Kao, J. C. Lee, and S. B. Yu, Strain and stress field in Taiwan oblique convergent system: Constraints from GPS observations and tectonic data, Earth Planet. Sci. Lett., 214, 115-127, 2003.

Igarashi, G. and H. Wakita, Tidal responses and earthquake-related changes in the water level of deep wells, J. Geophys. Res., 96, 42694278, 1991.

Inverson, R. M. and J. J. Major, Groundwater seepage vectors and the potential for hillslope failure and debris flow mobilization, Water Resour. Res., 22, 1543-1548, 1986.

Itaba, S. and N. Koizumi, Earthquake-related changes in groundwater levels at the Dogo hot spring, Japan, Pure Appl. Geophys., 164, 2397-2410, 2007.

Itaba, S., N. Koizumi, N. Matsumoto, M. Takahashi, T. Sato, R. Ohtani, Y. Kitagawa, Y. Kuwahara, T. Sato, and K. Ozawa, Groundwater level changes related to the ground shaking of the Noto Hanto Earthquake in 2007, Earth Planets Space, 60, 1153-1159, 2008a.

Itaba, S., N. Koizumi, T. Toyoshima, M. Kaneko, K. Sekiya, and K. Ozawa, Groundwater changes associated with the 2004 Niigata-Chuetsu and 2007 Chuetsu-oki earthquakes, Earth Planets Space, 60, 1161-1168, 2008 b.

Kao, H. and P.-R. Jian, Seismogenic patterns in the Taiwan region: Insights from source parameter inversion of BATS data, Tectonophysics, 333, 179-198, 2001.

Koizumi, N., Y. Kitagawa, N. Matsumoto, M. Takahashi, T. Sato, O. Kamigaich, and K. Nakamura, Pre-seismic groundwater level changes induced by crustal deformations related to earthquake swarms off the east coast of Izu Peninsula, Japan, Geophys. Res. Lett., 31, L10606, doi:10.1029/2004GL019557, 2004.

Lai, W.-C., N. Koizumi, N. Matsumoto, Y. Kitagawa, C.-W. Lin, C.-L. Shieh, and Y.-P. Lee, Effects of seismic ground motion and geological setting on the coseismic groundwater level changes caused by the 1999 Chi-Chi Earthquake, Taiwan, Earth Planets Space, 56, 873-880, 2004.

Matsumoto, K., T. Sato, T. Takanezawa, and M. Ooe, GOTIC2: a program for computation of oceanic tidal loading effect, J. Geod. Soc. Jpn., 47, 243-248, 2001.

Matsumoto, N., Y. Kitagawa, and N. Koizumi, Groundwater-level anomalies associated with a hypothetical preslip prior to the anticipated Tokai earthquake: Detectability using the groundwater observation network of the Geological Survey of Japan, AIST, Pure Appl. Geophys., 164, 2377 2396, 2007

Montgomery, D. R. and M. Manga, Streamflow and water well responses to earthquakes, Science, 300, 2047-2049, 2003.

Okada, Y., Internal deformation due to shear and tensile faults in a halfspace, Bull. Seismol. Soc. Am., 82, 1018-1040, 1992.

Quilty, E. and E. Roeloffs, Water level changes in response to the December 20, 1994 M4.7 earthquake near Parkfield, California, Bull. Seisimol. Soc. Am., 87, 310-317, 1997.

Roeloffs, E., Hydrologic precursors to earthquakes: A review, Pure Appl. Geophys., 126, 177-209, 1988.

Roeloffs, E., Poroelastic techniques in the study of earthquake-related hydrologic phenomena, Adv. Geophys., 137, 135-195, 1996.

Shin, T. C., K. W. Kuo, T. L. Lee, T. L. Teng, and Y. B. Tsai, A preliminary report on the 1999 Chi-Chi (Taiwan) earthquake, Seismol. Res. Lett., 71, 24-30, 2000.

Tamura, Y., T. Sato, M. Ooe, and M. Ishiguro, A procedure for tidal analysis with a Bayesian information criterion, Geophys. J. Int., 104, 507-516, 1991.

Todorovska, M. I. and M. D. Trifunac, Liquefaction opportunity mapping via seismic wave energy, J. Geotech. Geoenviron. Eng., 125, 10321042, 1999.

Wakita, H., Water wells as possible indicators of tectonic strain, Science, 189, 553-555, 1975.

Wang, C. Y., L. H. Cheng, C. V. Chin, and S. B. Yu, Coseismic hydrologicresponse of an alluvial fan to the 1999 Chi-Chi earthquake, Taiwan, Geology, 29, 831-834, 2001.

Watanabe, K., Strain variations of the Yamasaki fault zone, Southwest Japan, derived from extensometer observations Part 2-On the shortterm strain variations derived from strain steps-, Bull. Disast. Prev. Res. Inst., Kyoto Univ., 41, 53-85, 1991.

Water Resource Agency, Groundwater Resources in Taiwan, Ministry of Economic Affairs, 129 pp, 2005 (in Chinese).

W.-C. Lai, K.-C. Hsu, C.-L. Shieh, Y.-P. Lee, K.-C. Chung, N. Koizumi (e-mail: koizumi-n@aist.go.jp), and N. Matsumoto 